\title{
ICES Journal of
}

\section{Original Article}

\section{Wideband (15-260 kHz) acoustic volume backscattering spectra of Northern krill (Meganyctiphanes norvegica) and butterfish (Peprilus triacanthus)}

\author{
J. Michael Jech ${ }^{1 *}$, Gareth L. Lawson ${ }^{2}$, and Andone C. Lavery ${ }^{3}$ \\ ${ }^{1}$ NOAA, Northeast Fisheries Science Center, Woods Hole, MA 02543, USA \\ ${ }^{2}$ Biology Department, Woods Hole Oceanographic Institution, Woods Hole, MA 02543, USA \\ ${ }^{3}$ Department of Applied Ocean Physics and Engineering, Woods Hole Oceanographic Institution, Woods Hole, MA 02543, USA \\ *Corresponding author: tel: +1 508495 2353; fax: +1 508495 2115; e-mail: michael.jech@noaa.gov.
}

Jech, J. M., Lawson, G. L., and Lavery, A. C. Wideband (15-260 kHz) acoustic volume backscattering spectra of Northern krill (Meganyctiphanes norvegica) and butterfish (Peprilus triacanthus). - ICES Journal of Marine Science, 74: 2249-2261.

Received 11 August 2016; revised 7 March 2017; accepted 9 March 2017; advance access publication 28 August 2017.

Measurements of acoustic backscatter made over a wide frequency band have the potential for improved classification relative to traditional narrowband methods, by characterizing more fully the frequency response of scatterers. In January 2014, five wideband transceivers [Simrad EK80 Wideband Transceivers (WBTs)] and split-beam transducers with nominal centre frequencies of 18, 38, 70, 120, and 200 kHz were used to collect acoustic data spanning a nearly continuous $15-260 \mathrm{kHz}$ bandwidth. The acoustic samples were from ca. $2 \mathrm{~m}$ below the surface to the seabed in an area along the US continental shelf break. Bottom trawls and zooplankton nets were also used to sample scatterers contributing to selected features of the acoustic backscatter. Measurements of frequency-dependent volume backscattering strength (i.e. volume backscattering spectra) from aggregations of euphausiids (mostly Northern krill, Meganyctiphanes norvegica) clearly resolved the transition from Rayleigh to geometric scattering, consistent with modelled backscatter from the type and length of animals sampled with bongo nets. Volume backscattering spectra from aggregations dominated by butterfish (Peprilus triacanthus) revealed a frequency response that was suggestive of superimposed scattering by soft tissue and bone. Backscatter predicted by Kirchhoff ray mode models of butterfish corresponded to trends in the measured spectra, supporting the assumption that acoustic scattering by butterfish is dominated by soft tissue and vertebrae.

Keywords: acoustic backscatter, broadband, fish, zooplankton.

\section{Introduction}

Measurements of acoustic backscatter made over "wide" bandwidth provide more data on the frequency response of scatterers than over "narrow" bandwidth, offering the potential for improvements in species categorization, signal-to-noise ratio (SNR), and range resolution (Ehrenberg and Torkelson, 2000). We define wide bandwidth (i.e. wideband) acoustic data as that resulting from the transmission and reception (i.e. backscatter) of signals consisting of a single continuous band (i.e. broadband), multiple broadband signals, multiple narrow bandwidth (i.e. narrowband) signals (e.g. Holliday et al., 1989), or a combination of broadband and narrowband signals. The use of wideband data in underwater acoustics dates back to at least World War II where explosive sources (e.g. Love, 1975) provided broadband sound at lower (10-100s of $\mathrm{Hz}$ ) frequencies. Military and oil exploration led the development of safer broadband systems, with electronics that were more reliable and consistent, but applications to fisheries research and management have been slow to adopt the technology. Nevertheless, wideband systems have been custom-built for specific in situ (e.g. Zakharia, 1996; Nero et al., 2004; Lavery et al., 2010) or ex situ (Simmonds and Armstrong, 1990; Kjægaard et al., 1990; Conti and Demer, 2003; Stanton et al., 2003; Reeder et al., 2004; Conti et al., 2005; Lundgren and Nielsen, 2008) applications. 
Although custom systems are favoured for prototype development, commercial-off-the-shelf (COTS) systems are advantageous because maintenance, parts, and components are readily available, and software can be developed through commercial or open-source avenues. Wideband COTS systems for fisheries applications have been available for more than a decade (e.g. Ehrenberg and Torkelson, 2000) but their signal bandwidths were only sufficient to improve SNR and range resolution, not characterize volume backscattering spectra. Commercially available systems were modified for wideband target classification using mid-frequencies $(1.7-100 \mathrm{kHz})$ by Stanton and colleagues (Stanton, 2009; Stanton et al., 2010, 2012), and high frequencies (150-600 kHz) by Lavery et al. (2010). Simrad-Kongsberg's June 2015 release of a commercial WBT and control and data logging software (EK80) may stimulate application of wideband echosounding to fisheries and ecosystem surveys.

We present wideband $(15-260 \mathrm{kHz})$ acoustic volume backscattering spectra from aggregations of euphausiids (specifically Northern krill, Meganyctiphanes norvegica) and butterfish (Peprilus triacanthus) located along the edge of the continental shelf in the US mid-Atlantic Bight. These measurements are compared with net samples and theoretical models of acoustic backscatter to confirm to our interpretation of the data. In addition, we suggest notation for broadband volume backscatter across a frequency band and the approximation of volume backscattering at the nominal centre frequencies, which are useful for visualizing broadband data.

\section{Material and methods}

Data were collected during 8-12 January 2014 on the Fishing Vessel Karen Elizabeth (24-m western-rigged stern trawler) near the shelf break south of Cape Cod and east of Long Island, USA (Figure 1). The sampling equipment included a 4 -seam bottom trawl (4SBT; Politis et al., 2014), bongo nets (Posgay and Marak, 1980), narrowband Simrad ES60 and EK60, and wideband Simrad EK80 echosounders.

\section{Echosounders with hull-mounted transducers}

The ES60 transducers (Simrad Combi-B, single-beam 50- and 200- $\mathrm{kHz}$ with $10 \times 16^{\circ}$ and $7 \times 7^{\circ}$ beam widths, respectively; and a Simrad ES38-B, split-beam $38-\mathrm{kHz}$ with $7 \times 7^{\circ}$ beam width) were mounted on the hull of Karen Elizabeth. These systems were calibrated with a $38.1-\mathrm{mm}$ diameter sphere made from tungsten carbide with 6\% cobalt binder (WC) (Foote et al., 1987), immediately following the wideband calibrations (described below), in Providence, RI, USA. The "triangle-wave" error, inherent in ES60 data, was removed (Demer et al., 2015) before further processing using commercial software (Echoview v6+, Echoview Software Pty Ltd, Hobart, Tasmania).

\section{Echosounders with towed transducers}

The wideband echosounder system was composed of six WBTs (hardware Rev. 0.13), EK80 software (version 1.2.5087.17756), and six split-beam transducers with nominal centre frequencies $\left(f_{\text {nom }}\right)$ of $18,38,70120,200$, and $333 \mathrm{kHz}$ (Simrad ES18, ES38-B, ES70-7C, ES210-7C, ES200-7C, and ES333-7C, respectively). Data from the $333-\mathrm{kHz}$ WBT were too noisy to use and are not presented here. Each WBT can transmit and receive signals from 10 to $500 \mathrm{kHz}$, but the functional bandwidth is limited, typically to an octave or less, by the operational bandwidth of the

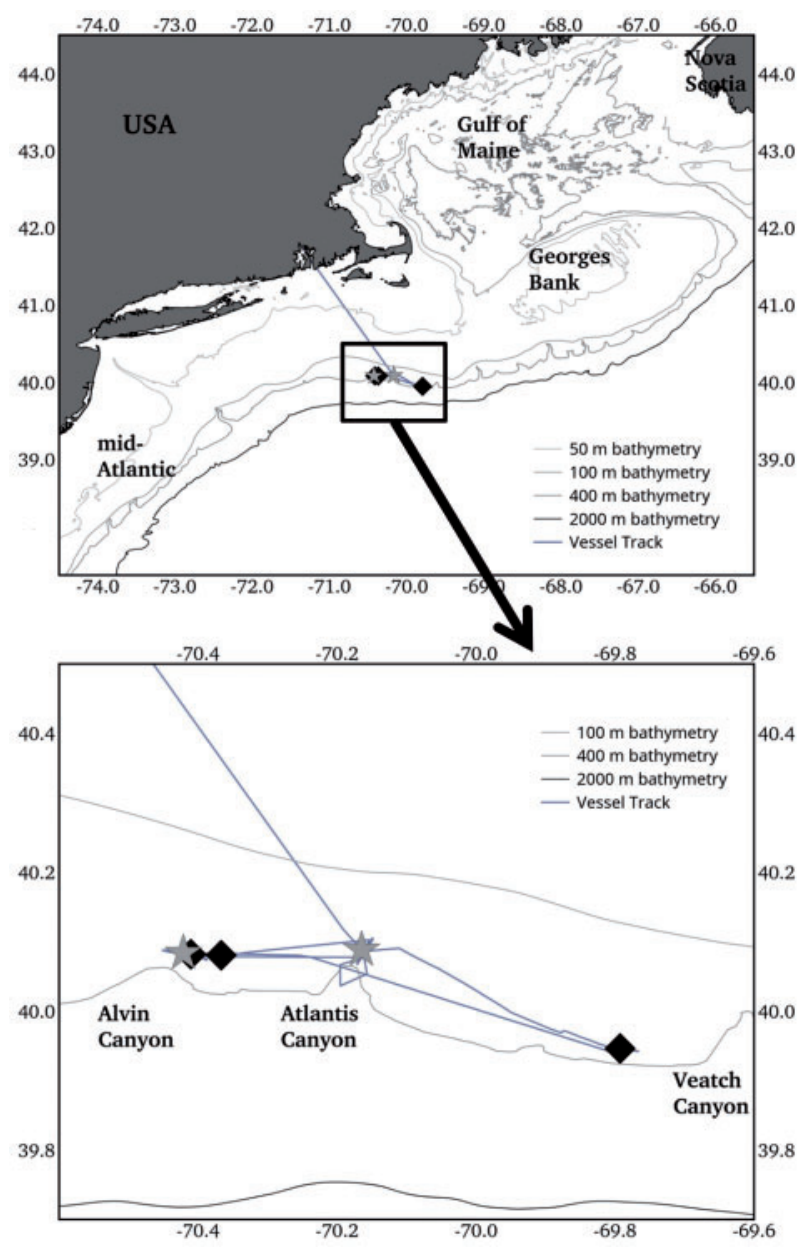

Figure 1. Data collection sites. Stars denote bongo sampling sites and diamonds denote 4SBT hauls.

attached transducer (Table 1). The transducers were mounted on an aluminum deadweight frame (Figure 2) that was deployed near the sea surface from the port quarter of Karen Elizabeth, while drifting. Tow speeds up to $5 \mathrm{kts}$ resulted in transducer instability and increased noise. The broadband signals consisted of 1.024 ms linear chirps with a $10 \%$ slope (i.e. "ramp" or "taper") for all bands. At the time of data collection, the transmit pulse slope parameter choices were 5 and $10 \%$, which correspond to the current Simrad terminology of "fast" and "slow", respectively, in the EK80 acquisition software. Generally, the pulses from each WBT were transmitted sequentially, from lowest to highest frequency, with an interval of $500 \mathrm{~ms}$. In addition, data were collected with simultaneous transmissions at all frequencies. Data were collected from 15 to $260 \mathrm{kHz}$, although post-processing led to gaps in the spectrum (Table 1). Each WBT and transducer pair was calibrated twice. The first calibration was performed prior to the shipboard measurements, using 15-, 21.2-, and 38.1-mm diameter WC spheres, in the tank facility at the University of New Hampshire, USA (www.ccom.unh.edu/facilities/test-tanks/ engineering-tank). The transducers were mounted in the aluminum frame (without tail fin) with the acoustic axes oriented horizontally and the spheres sequentially located at 6- to 8 -m range. 
Table 1. EK80 data acquisition parameters.

\begin{tabular}{lccl}
\hline Transducer & $\begin{array}{c}\text { Transmit/receive } \\
\text { frequency band }(\mathbf{k H z})\end{array}$ & $\begin{array}{c}\text { Selected frequency } \\
\text { band }(\mathbf{k H z})\end{array}$ & $\begin{array}{l}\text { Transmit } \\
\text { power }(\mathbf{W})\end{array}$ \\
\hline ES18-11 & $15-25$ & $15.4-23.3$ & 400 \\
ES38D & $25-45$ & $32.0-44.5$ & 400 \\
ES70-7D & $45-95$ & $53.0-94.0$ & 500 \\
ES120-7C & $95-160$ & $100.0-158.0$ & 125 \\
ES200-7C & $160-260$ & $160.0-260.0$ & 75 \\
ES333-7C & $260-400$ & $262.0-395.0$ & 25 \\
\hline
\end{tabular}

The "Transmit/Receive Frequency Band" represents the upper and lower frequency limits of the transmit and receive signal set in the EK80. The "Selected Frequency Band" represents the upper and lower frequency limits that were used for post-processing the broadband data for each channel.

a Limited amounts of test data were collected from the ES333-7C but are not reported in this article.

These measurements were used to determine the operational bandwidths for each transducer.

At the conclusion of the shipboard measurements, each WBT and transducer pair was calibrated using 21.2- and 38.1-mm diameter WC spheres, dockside in Providence, RI, USA. Calibration procedures followed published methods (Stanton and Chu, 2008; Stanton et al., 2010; Lavery et al., 2010, 2017), and resulted in estimates of frequency-dependent gain, $G(f)$, for each transducer (see Lavery et al., 2017). In contrast, calibrations of narrowband echosounders (e.g. EK60) result in estimates of $G$ only at $f_{\text {nom }}$ (Lunde et al., 2013).

Wideband data from each WBT were processed (see Lavery et al., 2017), to obtain measurements of frequency-dependent volume backscattering strength $\left(S_{\mathrm{V}}(f), \mathrm{dB}\right.$ re $\left.\mathrm{m}^{-1}\right)$, i.e. volume scattering spectra. Using matched filter (MF) processing (Turin, 1960; Chu and Stanton, 1998; Stanton and Chu, 2008), the data had improved temporal (and hence range) resolution, proportional to the signal bandwidth $B(\mathrm{~Hz})$, and increased SNR, by $\sim 2 B T$, where $T$ is the signal duration (s) (Stanton and Chu, 2008, and references therein). Using MF processing, $S_{\mathrm{V}}(f)$ at range $r$ is given by (Lavery et al., 2010; Stanton et al., 2010):

$$
\begin{aligned}
S_{\mathrm{V}}(f)= & 10 \log _{10} \frac{\left\langle|\gamma(f)|^{2}\right\rangle}{P_{\mathrm{T}} K_{\mathrm{T}}}-10 \log _{10}\left(L_{\mathrm{TL}}(f)\right)^{2}-10 \log _{10} V(f) \\
& -2 G(f)
\end{aligned}
$$

where $P_{\mathrm{T}}$ is the transmitted power (Watts), and $K_{\mathrm{T}}=2 Z \frac{\lambda_{\text {nom }}^{2}}{16 \pi^{2}}$ is a Simrad-supplied factor intended to account for the received power in a matched load based on generic transducers, where $Z=75 \Omega$ is the equivalent impedance for this system, and $\lambda_{\text {nom }}$ is the wavelength at the nominal frequency (e.g. at the centre of the spectral band). $L_{\mathrm{TL}}(f)$ is the frequency-dependent transmission loss on a linear scale attributable to spherical spreading and seawater absorption, and is given by:

$$
L_{\mathrm{TL}}(f)=\frac{10^{-\alpha(f) r / 10}}{r^{2}}
$$

where $\alpha(f)\left(\mathrm{dB} \mathrm{m}^{-1}\right)$ is the frequency-dependent attenuation factor (Francois and Garrison, 1982a, b). $|\gamma(f)|$ is the absolute value of the fast Fourier transform (FFT) of the compressed pulse

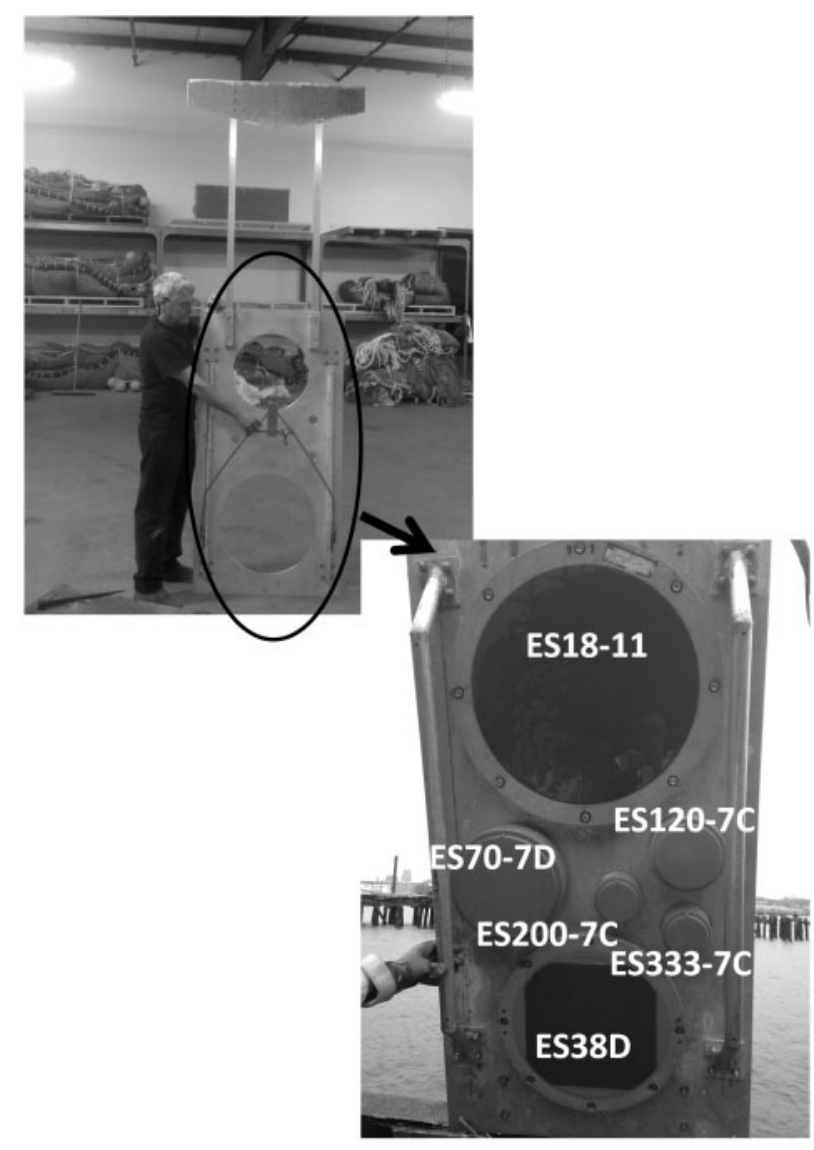

Figure 2. Transducers and aluminum deadweight tow body. Simrad split-beam transducer models are shown for each transducer.

output of the range of interest, and $\langle\ldots\rangle$ denotes the average over multiple transmissions. $V(f)$ is the frequency-dependent insonified volume at range $r$, and is given by

$$
V(f)=\frac{1}{2} c_{\mathrm{w}} \tau_{\mathrm{eff}} r^{2} \Psi_{\mathrm{D}}(f)
$$

where $\tau_{\text {eff }}$ is the duration of the time window after the MF processing, $c_{\mathrm{W}}$ is the speed of sound at range $r$, and $\Psi_{\mathrm{D}}(f)$ is the equivalent beam angle (Urick, 1983). Here we use the theoretical, frequency-dependent beam angle for calculations of frequencydependent volume backscatter.

To display the calibrated MF data, which are 3D (distance/ time, range/depth, and frequency), as a 2D “echogram" used for narrowband data, it is necessary to account for: (i) contributions from all frequency components of the transmitted signal for that channel, (ii) changes in sampling volume and transmission loss with range and frequency, and (iii) the frequency-dependent calibration. These are achieved by calculating the absolute value of the MF output as a function of range, and correcting for all other

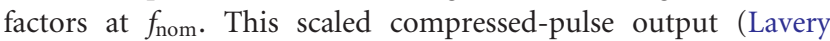
et al., 2010) at the nominal frequency, $\tilde{S}_{v}\left(f_{\text {nom }}\right)\left(\mathrm{dB} \mathrm{re} \mathrm{m}^{-1}\right)$, does not fully account for the frequency dependence of the various factors, but is adequate for illustration purposes because it approximates $S_{\mathrm{v}}(f)$ at the nominal centre frequency. 


$$
\begin{aligned}
\tilde{S}_{\mathrm{v}}\left(f_{\text {nom }}\right)= & 10 \log _{10} \frac{\left\langle|y(t)|^{2}\right\rangle}{P_{\mathrm{T}} K_{\mathrm{T}}}-10 \log _{10}\left|L_{\mathrm{TL}}\left(f_{\text {nom }}\right)\right|^{2} \\
& -10 \log _{10} V\left(f_{\text {nom }}\right)-2 G\left(f_{\text {nom }}\right)
\end{aligned}
$$

where $|y(t)|$ is the absolute value of the compressed-pulse output of the received signal.

\section{Biological data}

To verify the species and size composition of the echogram features, bongo nets and the 4SBT were towed within $125 \mathrm{~m}$ of the sea surface and near the bottom, respectively, at multiple sites (Figure 1). Zooplankton were collected with a $61-\mathrm{cm}$ diameter bongo net equipped with $335-\mu \mathrm{m}$-mesh nets towed obliquely at ca. 3-4 kts, the slowest vessel speed achievable. The bongo net wire was deployed at ca. $50 \mathrm{~m} \mathrm{~min}^{-1}$ and recovered at ca. $20 \mathrm{~m}$ $\min ^{-1}$. A time-depth recorder was deployed on the initial tows, but was lost partway through the cruise. The 4SBT was towed in accordance with NEFSC bottom-trawl survey protocols (Politis et al., 2014), but with tow durations adjusted to optimize catches.

4SBT catches were sorted to species, each species weighed en masse, and lengths were measured for up to 150 randomly sampled individuals. Bongo samples were preserved in $4 \%$ buffered formalin and later processed in the laboratory. Samples were examined qualitatively for overall species composition. In tows dominated by euphausiids, all euphausiids were removed, identified to species, and measured for length (Standard Length 3 , from the posterior base of the eye stalk to the end of the sixth abdominal segment; Mauchline, 1980).

\section{Acoustic modelling}

Target strength (TS, $\mathrm{dB}$ re $1 \mathrm{~m}^{2}$ ) spectra for euphausiids (i.e. an elongated and fluid-like scatterer) was generated over the frequency band of the acoustic measurements using a DistortedWave Born Approximation (DWBA)-based bent cylinder model as developed for Antarctic krill (Euphausia superba) in Lawson et al. (2006) and re-parameterized for M. norvegica as in Wiebe et al. (2013). The model was parameterized using a length-towidth ratio of 18.2, a normal distribution of angles of orientation with a mean of $0^{\circ}$ and $S D$ of $27^{\circ}$, and density $(g=1.039)$ and sound speed $(h=1.038)$ contrasts from Calise (2009). The length of the equivalent cylinder was taken as the distance from the anterior tip of the eye to the end of the sixth abdominal segment (Lawson et al., 2006) and a correction factor of 1.095 was used to scale the lengths measured in bongo net samples. All euphausiid lengths presented here refer to this "acoustic length" (Lawson et al., 2008). Individual acoustic backscattering cross-sections $\left(\sigma_{\mathrm{bs}}, \mathrm{m}^{2}\right)$ were calculated from 1 to $275 \mathrm{kHz}$ at $1 \mathrm{kHz}$ intervals for each acoustic length of euphausiid sampled in the bongo net and then averaged over all individuals, thereby accounting for the sampled length distribution.

TS spectra for butterfish were generated with a modified version of the Kirchhoff ray-mode (KRM) model (Clay and Horne, 1994). Lateral and dorsal views of one live (142-mm caudal length (CL) anaesthetized with MS-222) and two previously frozen (165- and 145-mm CL) butterfish were radiographed (Figure 3), and silhouettes of the body and vertebral column were digitized at 1-mm resolution (e.g. Jech and Horne, 1998). The radiographs were taken at $40-\mathrm{cm}$ focal length and $70 \mathrm{kV}$, with exposures of 0.126 and $1.103 \mathrm{~s}$ and 2.7 and $3.3 \mathrm{~mA}$ for the lateral and dorsal radiographs, respectively. The digital silhouettes were converted

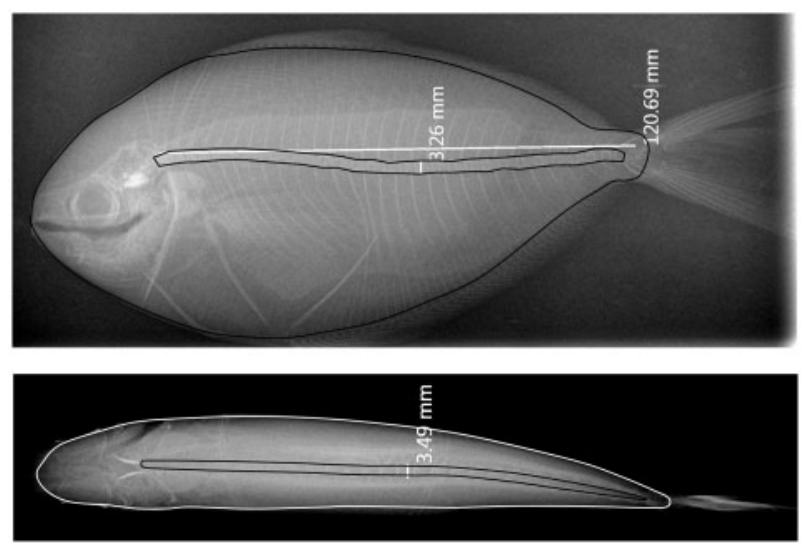

Figure 3. Lateral (upper panel) and dorsal (lower panel) radiographs of a previously frozen $165-\mathrm{mm} \mathrm{CL}$ butterfish. The displayed length measurements were applied manually by the radiographer using the radiograph viewing software. Silhouettes (i.e. outlines of the fish body and vertebral column) were those used in the KRM model for this individual.

to equivalent cylinders (Horne and Jech, 1999) and reduced scattering length (RSL) was calculated from 10 to $400 \mathrm{kHz}$ at $1-\mathrm{kHz}$ intervals.

The KRM algorithm of Clay and Horne (1994) was modified so that backscatter $\left(90^{\circ}\right.$ dorsal incidence) by the vertebral column was computed as a fluid-filled object embedded in the fish body (rather than the typical implementation where the swimbladder is represented as a gas-filled soft target) and the sound speed and density ratios (h and $\mathrm{g}$ ) for the vertebral column were calculated as the ratio of the sound speed and density of the vertebral column relative to those of the fish body, not to the surrounding water. Seawater sound speed $\left(c_{\text {water }}=1477.4 \mathrm{~m} \mathrm{~s}^{-1}\right)$ and density $\left(\rho_{\text {water }}=1026.8 \mathrm{~kg} \mathrm{~m}^{-3}\right)$ from Jech et al. (2016) were used. Material properties (sound speed and density) of butterfish flesh ( $c_{\text {flesh }}$ and $\left.\rho_{\text {flesh }}\right)$ and vertebrae $\left(c_{\text {vertebrae }}\right.$ and $\left.\rho_{\text {vertebrae }}\right)$ were not directly available. Chosen material property values were constrained such that the reflectivity coefficient (Clay and Medwin, 1977) of fish flesh ranged between 1.2 and 6\% (Cushing, 1973), and was $\sim 24 \%$ for fish bone (Wright and Colling, 1995); the density ratio, (i.e. $g=\frac{\rho_{\text {flesh }}}{\rho_{\text {water }}}$ ) for fish flesh ranged between 1.002 and 1.025; and the sound speed ratio (i.e. $\left.h=\frac{c_{\text {flesh }}}{c_{\text {water }}}\right)$ was about 1.025 for Atlantic mackerel (Gorska et al., 2005). Given these limits, sound speeds of 1514.2 and $1700.0 \mathrm{~m} \mathrm{~s}^{-1}$ and densities of 1052.5 and $1400.0 \mathrm{~kg} \mathrm{~m}^{-3}$ were used for the fish flesh and vertebrae, respectively.

To compare theoretical TS $(f)$ to $S_{\mathrm{v}}(f)$ of in situ scatterers, the length distribution was used to weight the TS $(f)$. The RSL at each $1-\mathrm{kHz}$ frequency interval and 1-mm length interval was scaled by the proportion of that length class in the length distribution, and then the scaled RSLs were summed over the length intervals to calculate a length weighted backscattering cross-sectional area $\left(\overline{\sigma_{\mathrm{bs}}}\right)$ at each $1-\mathrm{kHz}$ frequency interval:

$$
\overline{\sigma_{\mathrm{bs}}}(f)=\sum_{i=1}^{N_{\ell}}\left[\operatorname{RSL}\left(f, \ell_{i}\right) * \ell_{i} * p\left(\ell_{i}\right)\right]
$$

where $N$ is the number of length classes $(\ell), p$ is the proportion of the $i^{\text {th }}$ length class, and the proportions sum to 1 . 


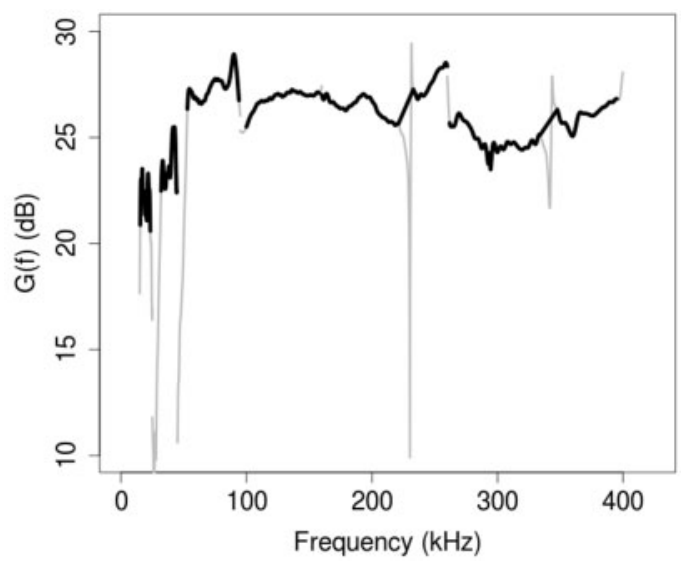

Figure 4. Calibration curves $[G(f)]$ for each broadband channel. The grey lines represent the $G(f)$ for the full transmit/receive band and the thick black lines represent the selected portion of the $G(f)$ curve (Table 1) used to post-process each channel. The spikes in the 200 (between 221.0 and $233.0 \mathrm{kHz}$ ) and 333 (between 334.0 and $347.7 \mathrm{kHz}) \mathrm{kHz} G(f)$ curves were removed by linearly interpolating over each section of its $G(f)$ curve.

\section{Results Calibration}

Calibrated $G(f)$ was generated for each WBT/transducer pair (Figure 4) using the calibrations conducted in the large tank. The dockside calibrations confirmed the precision of these $G(f)$ measurements. The selected bandwidth used in post-processing for each WBT/transducer pair was usually less than the transmit/receive band (Table 1; Figure 4). The useful bandwidths were selected based on visual inspection of $G(f)$ and ad hoc decisions to maintain a ca. $<3 \mathrm{~dB}$ dynamic range between the minimum and maximum $G$ with each $G(f)$. Outside of these bands, the resulting $S_{\mathrm{v}}(f)$ increased implausibly, suggestive of poorly constrained $G(f)$. In addition, the peaks and nulls in $G(f)$ were replaced by linear interpolations (Figure 4). These artifacts, resulting from constructive and destructive interference patterns inherent in the sphere TS $(f)$, would otherwise degrade data analysis and interpretation (Lavery et al., 2017).

\section{Volume backscattering measurements and comparison to theoretical models}

During the night of 10 January 2015 at the head of Atlantis Canyon (Figure 1), a scattering feature was observed within $60 \mathrm{~m}$ of the sea surface (Figure 5$)$. The $\tilde{S}_{\mathrm{v}}\left(f_{\text {nom }}\right)$ was lowest in the 18$\mathrm{kHz}$ band and strongest in the $120-$ and $200-\mathrm{kHz}$ bands, suggesting a fluid-like scatterer. Bongo-net samples from the vicinity of this feature were dominated by euphausiids. Smaller fluid-like scatterers (copepods) that would contribute negligibly to overall scattering were also present at lower abundances while smaller, strongly scattering elastic-shelled taxa (i.e. thecosomatous pteropods) that can at times dominate scattering even at low abundances (Stanton et al., 1994; Lavery et al., 2007) were absent. The scattering layer thus appeared attributable to euphausiids, specifically $M$. norvegica, which comprised $99 \%$ of the sampled euphausiids by weight. Their lengths ranged from 14 to $33 \mathrm{~mm}$, with a mean and standard deviation of 22.4 and $3.2 \mathrm{~mm}$, respectively (Figure 6). To characterize $S_{\mathrm{v}}(f)$ for this scattering feature, regions within and outside of the euphausiid patch were visually selected from the echograms (Figure 5), and $S_{\mathrm{v}}(f)$ for each band were combined into a single wideband spectrum (Figure 7). The spectra were combined by applying an FFT over 1-m depth bins for individual pings, and then frequency-dependent spectra were averaged in linear space over range and ping number. Single pings with $1-\mathrm{m}$ depth bins produced highly variable spectra (Figure 7a and b), while averaging spectra over a larger region (i.e. multiple pings and depth bins) produced a smoother spectrum (Figure 7b), which highlighted the overall scattering response for the euphausiids in that feature. The SNR, based on comparison of spectra from within the feature to that from outside of the feature, was about $10 \mathrm{~dB}$ in the $15-25 \mathrm{kHz}$ band and increased to nearly $30 \mathrm{~dB}$ at the higher-frequency bands for this patch (Figure 7c). In lower-amplitude backscattering regions, spikes were evident in the spectra near 131 and $219 \mathrm{kHz}$ and to a lesser extent near 199-212 and $234 \mathrm{kHz}$ (Figure 7c). These spikes were also evident when data were collected in passive mode (not shown) and hence appear to be due to noise. Spectra averaged for different depths and pings within the main patch and one region of lower backscatter above the main patch showed overall very similar shapes, with only slight variations in the location of the transition from Rayleigh (acoustic wavelength much larger than the scatterer size) to geometric (acoustic wavelength much smaller than the scatterer size) regions, consistent with generally constant length distributions. Magnitudes of the spectra differed between regions, however, consistent with variations in abundance (Figure 7c).

The $M$. norvegica length distribution was used to generate a predicted TS $(f)$ over the bandwidth of the measured $S_{\mathrm{v}}(f)$ data (Figure $7 \mathrm{~d}$ ). Backscattering levels observed in the euphausiid patch were high, and the predicted $\operatorname{TS}(f)$ was scaled by a density of 700 ind $\mathrm{m}^{-3}$ to generate a predicted $S_{\mathrm{v}}(f)$ curve for comparison to measured data. In situ euphausiid densities estimated from the bongo samples were ca. 0.5 ind $\mathrm{m}^{-3}$, much lower than those assumed in calculating the predicted $S_{\mathrm{v}}(f)$ response curve and likely suggesting that the net system did not pass directly through the patch, avoidance by euphausiids of the bongo net is quite high (as reported in Wiebe et al., 2013), or both. Unfortunately, time-depth recorder information was not available for this tow and hence the exact depth range sampled and proximity to the acoustic patch are uncertain. It is important to note though that while the magnitude of the predicted spectrum is a function of the assumed density (which was adjusted to allow the predicted and measured curves to overlay one another and hence is not independent of the acoustic data), its shape is determined by independent information on the size of euphausiids from the net samples combined with the fluid-like scattering model. The predicted and measured $S_{\mathrm{v}}(f)$ differ by $2-5 \mathrm{~dB}$ (predicted less than measured) at the lower bands and $\angle 3 \mathrm{~dB}$ at the higher bands (Figure $7 \mathrm{~d}$ ).

The TS $(f)$ predicted by the KRM model for the live $142-\mathrm{mm}$ butterfish shows numerous peaks and sharp nulls for the fish body, with relatively flat amplitudes from 10 to $400 \mathrm{kHz}$. In contrast, $\operatorname{TS}(f)$ for the vertebral column has fewer peaks and nulls, the amplitude is comparable to that of the body from 10 to about $100 \mathrm{kHz}$ and above about $375 \mathrm{kHz}$, and exceeds that of the body between about 100 and $375 \mathrm{kHz}$ (Figure 8a). These patterns are indicative of weak scatterers, where the larger (i.e. thicker) body has nulls that are closer together in frequency space than the nulls from the vertebrae, which is a smaller anatomical feature 

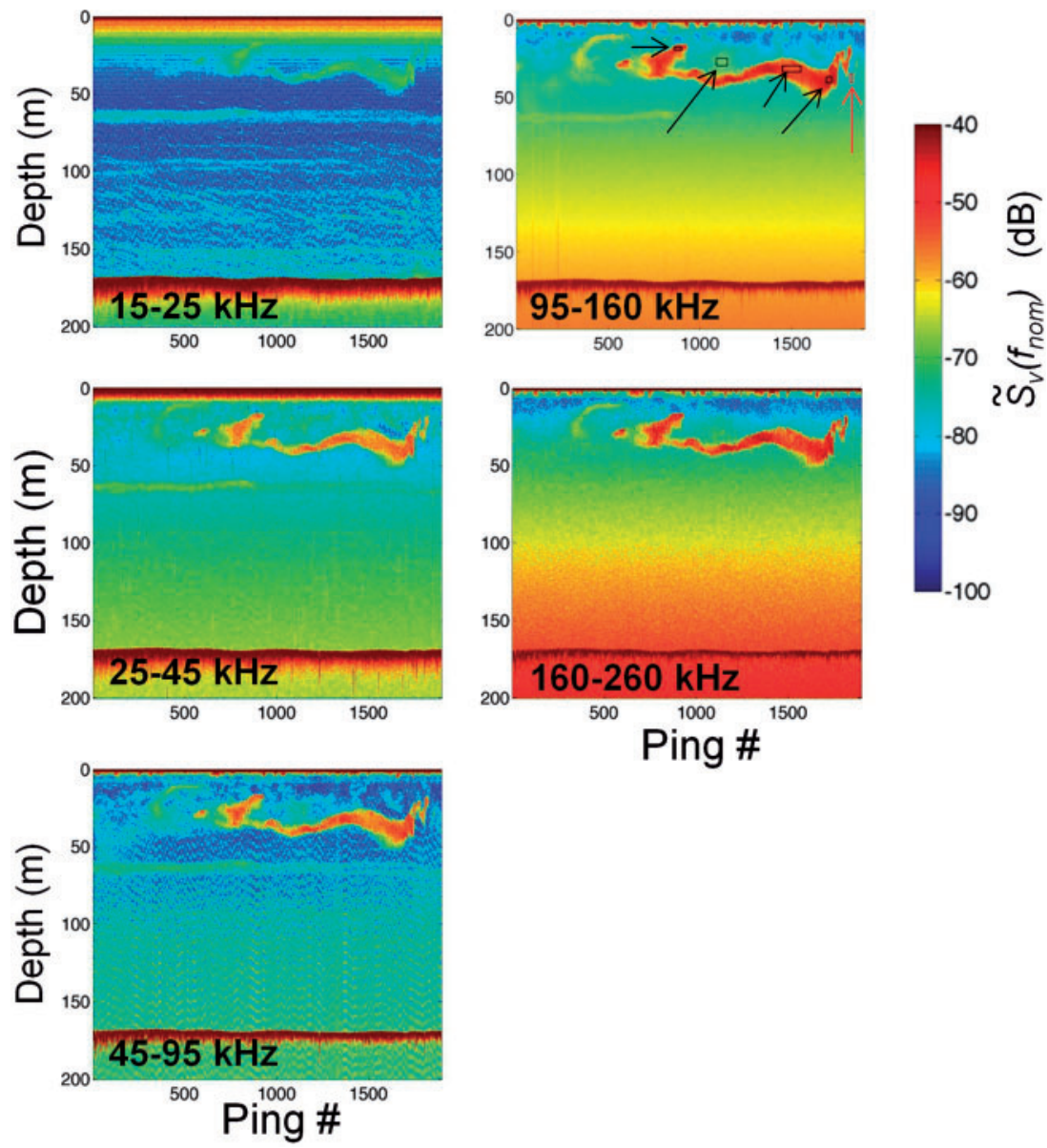

Figure 5. Scaled compressed-pulse output $\left[\tilde{S}_{\mathrm{v}}\left(f_{\text {nom }}\right)\right]$ echograms of broadband data collected 2034-2108 (Eastern Standard Time, EST) on 10 January. The large scattering feature between 20 and $50 \mathrm{~m}$ depth is a euphausiid patch. Pings 1-1688 were collected with all five channels transmitting simultaneously, after which data were collected in sequential mode. Black boxes in the $95-160 \mathrm{kHz}$ channel echogram represent regions where spectra were calculated within and near the euphausiid patch and the far-right red box represents "open" water where the spectrum was calculated as an approximation for background noise levels.

(Figure 3). The peaks in the vertebra and whole fish scattering curves have a larger-scale trend which increases in amplitude from 10 to about $200 \mathrm{kHz}$, and then decreases in amplitude to $400 \mathrm{kHz}$. This decrease at our "higher" frequencies is part of an overall pattern (not shown) where TS $(f)$ eventually increases with increasing frequency.

Around sunset on 10 January 2015, in water depths of ca. 160 $\mathrm{m}$ along the continental-shelf edge, between Alvin and Atlantis Canyons (Figure 1), a scattering feature was observed, initially on the seabed and then rising about 20-30 $\mathrm{m}$ (Figure 9). The 18 and $38 \mathrm{kHz} \quad \tilde{S}_{\mathrm{v}}\left(f_{\text {nom }}\right)$ was lower than that for the higherfrequencies, again suggesting a fluid-like scatterer. Spectra from single pings and individual $1-\mathrm{m}$ depth bins again showed strong variability (Figure 10a and b). Spatially-averaged spectra for multiple region and depths within the scattering feature were flat from 15 to about $125 \mathrm{kHz}$, then increased from $\sim 125$ to $160 \mathrm{kHz}$, and leveled again about $160 \mathrm{kHz}$ (Figure 10b and c). The spectra from "open" water at different depths surrounding the scattering feature were similar to those from within the layer, but were $10 \mathrm{~dB}$ lower in the lower-frequency bands and $2-5 \mathrm{~dB}$ lower in the higher-frequency bands (Figure 10c). This result suggested that the SNR for $\tilde{S}_{\mathrm{v}}\left(f_{\text {nom }}\right)$ from the feature was

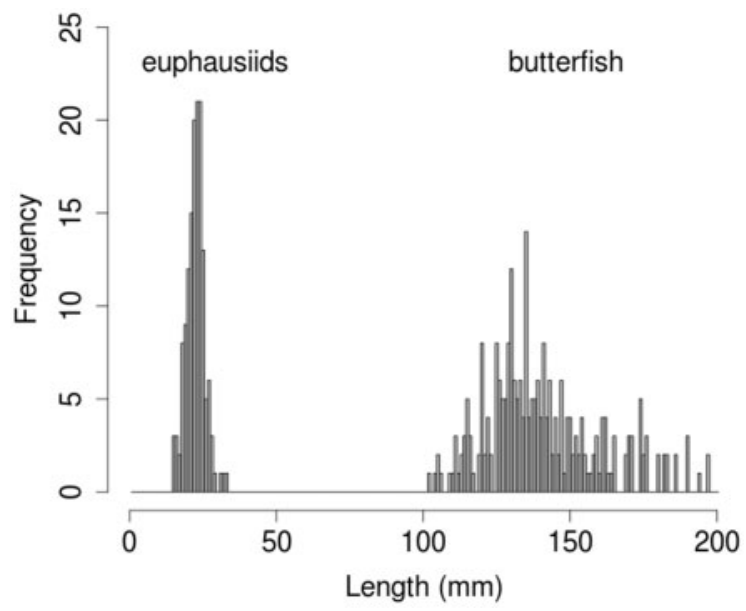

Figure 6. Length-frequency distributions of Northern krill (shorter lengths labelled "euphausiids") captured in a bongo net tow conducted in the vicinity of the shallow scattering feature (Figure 4) and of butterfish FLs (longer lengths labelled "butterfish") subsampled from a 4SBT tow conducted in the vicinity of the deep scattering feature (Figure 8). 
acceptable. Again, there were noise spikes near 131, 219, and $234 \mathrm{kHz}$, and smaller spikes in the $180-212 \mathrm{kHz}$ band (Figure $10 \mathrm{~b}$ and c).

A bottom trawl haul in the location of this scattering feature, albeit 5 hours earlier, caught $4096.1 \mathrm{~kg}$, dominated by butterfish ( $97.6 \%$ by weight), with $0.5 \%$ squid (Loligo and Illex sp.), $0.9 \%$ spiny dogfish (Squalus acanthius), $0.4 \%$ four-spot flounder (Hippoglossina oblonga), and $0.5 \%$ other by weight. The sampling volume for this tow was ca. $41000 \mathrm{~m}^{3}$ (10-min tow duration at 3 kts with a mouth opening of $\sim 45.5 \mathrm{~m}^{2}$ when fishing). The numeric density of butterfish was estimated at 1.9 ind $\mathrm{m}^{-3}$ for this tow by scaling the catch weight to numbers of fish using the length-weight regression for winter- or spring-caught butterfish $\left(\ln (\mathrm{W})=-11.6824+3.293^{*} \ln (\mathrm{FL})\right.$; Wigley et al., 2003). Butterfish fork lengths (FLs) were on average $14.0 \mathrm{~cm}$ with standard deviation $2.1 \mathrm{~cm}$ (Figure 6). The butterfish length distribution (Figure 6) was used to weight the KRM TS $(f)$ (Figure 8a) using Equation (5). The length-weighted $\overline{\mathrm{TS}}(f)=10 \log _{10}\left(\overline{\sigma_{\mathrm{bs}}}(f)\right)$ was scaled by $-8 \mathrm{~dB}$ (ca. 0.16 ind $\mathrm{m}^{-3}$ ) to match the $S_{\mathrm{v}}(f)$ amplitude (Figure 10d).

\section{Discussion}

We present in-situ acoustic backscattering measurements on euphausiids and butterfish over more than four octaves of bandwidth. The species composition of the euphausiid aggregation was verified using nets and the $S_{\mathrm{v}}(f)$ was compared with theory. Both lines of evidence support our interpretation that the scattering aggregation was composed of euphausiids. Trawl catch data confirmed that the demersal scatters were butterfish, for which we present a theoretical scattering model. Butterfish have a complicated swimbladder ontogeny where the swimbladder is air filled and then lipid as the fish grows from juvenile to adult states. Therefore, the $\operatorname{TS}(f)$ for butterfish will evolve from that for a fish with a gas-filled-swimbladder (e.g. like a clupeid; Reeder et al., 2004; Stanton et al., 2010) to that for a fish without a swimbladder or a lipid-filled swimbladder (e.g. similar to Atlantic mackerel; Simmonds and Armstrong, 1990; Korneliussen, 2010). Our measured and our KRM-based TS $(f)$ for the body, vertebral column, and combined (coherent summation of the body and vertebral column) are consistent with measurements of individual, ex-situ Atlantic mackerel (Scomber scombrus) (Nesse et al.,

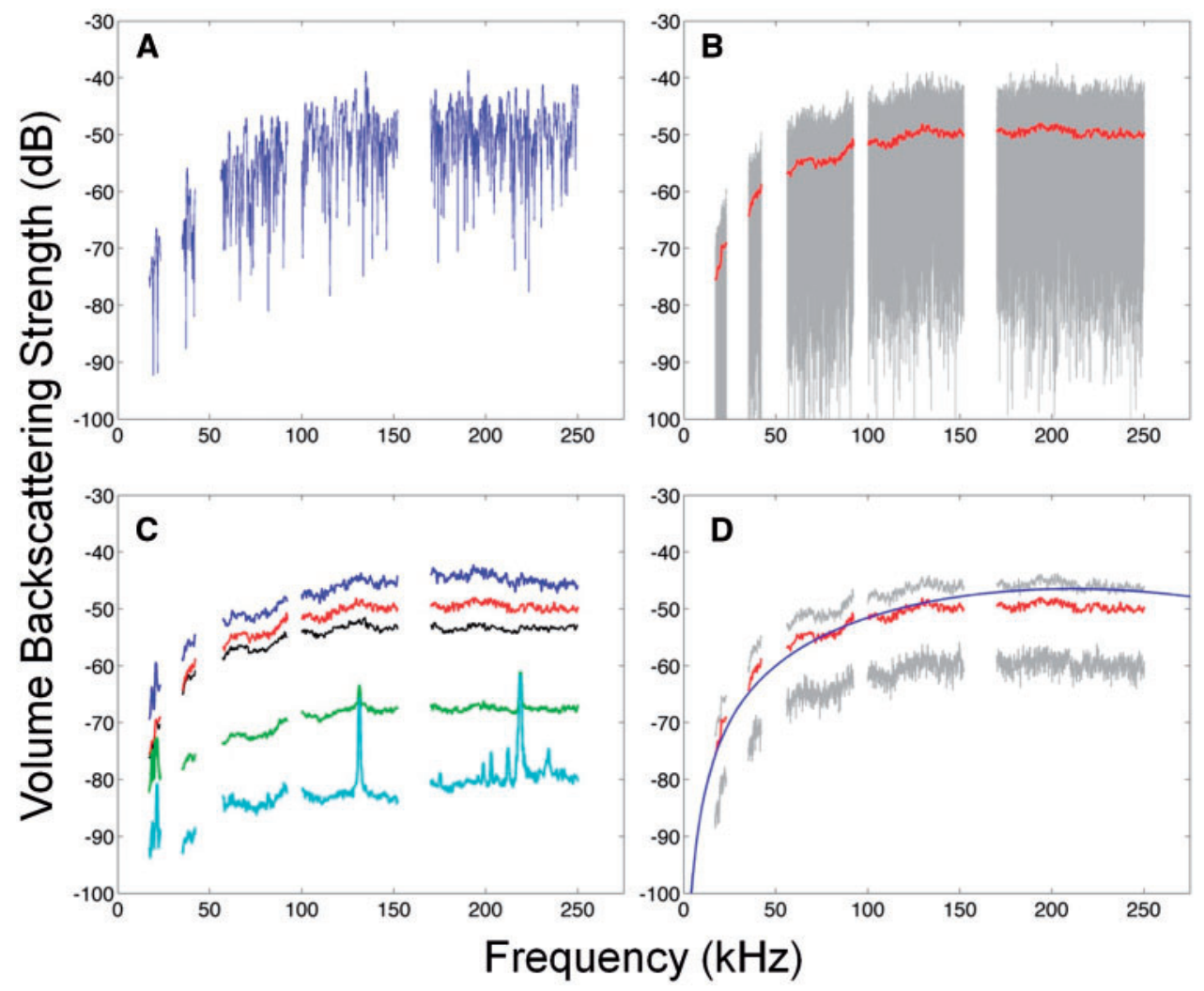

Figure 7. Volume backscattering spectra $\left[S_{v}(f)\right]$ from the areas denoted in and out of the euphausiid patch in Figure 5. Panel (a) shows the spectrum from a single ping (ping number 1689 in Figure 5) averaged over a single 1-m depth bin within the krill patch. Panel (b) shows the spectra (grey lines) from all 1-m depth bins within a 31 ping $\times 4 \mathrm{~m}$ depth region of the krill patch (pings 1689-1719 and 37-41 $\mathrm{m}$ in Figure 5) and the average spectrum for this region (red line). Panel (c) shows spectra from different regions of varying sizes and depths within the main patch (red line as in panel (b), blue and black lines correspond to pings 860-900 and depths 18-20 m and pings 1450-1550 and 30-34 $\mathrm{m}$, respectively), a spectrum from a lower-scattering region just above the main patch (green line, pings 1090-1150 and 25-30 m), and a spectrum from outside the patch but at similar depths in "open" water (cyan line, pings 1818-1833 and 35-41 m). This latter spectrum was used to approximate noise levels. Note that at the time the data shown by the blue, black, and green lines were collected (i.e. for pings 1-1688), the system was transmitting in simultaneous mode, while for pings 1689 onwards it was in sequential mode. Panel (d) shows the average spectrum (red line, panel b) as well as the 10th and 90th percentiles (grey lines) of the distribution of spectra from the region and the theoretical volume backscattering response of fluid-like scatterers modelled over the net-sampled euphausiid acousticlength distribution and assuming a numerical density of 700 individuals $\mathrm{m}^{-3}$ (blue line). 

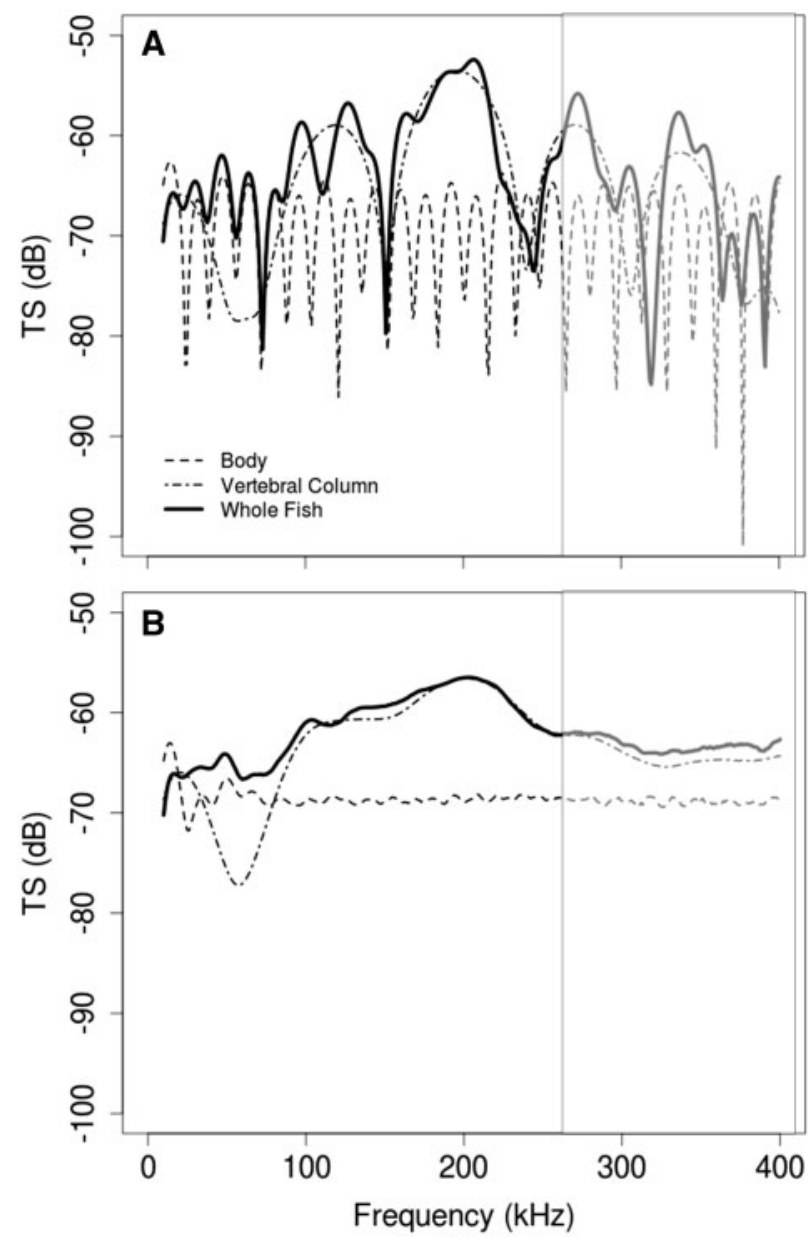

Figure 8. KRM TS response curves for a single, $142-\mathrm{mm} \mathrm{CL}$ butterfish at dorsal incidence. The upper panel (a) shows the body only (dashed line), vertebral column only (dash-dot line) and the combined body and vertebrae (solid line). The lower panel (b) shows the TS response curves for the same anatomical parts weighted by the length-frequency distribution of butterfish sampled by the 4SBT haul. The shaded area from 260 to $400 \mathrm{kHz}$ highlights frequencies greater than those used for measurements presented in this study, but are shown to provide context for the KRM predictions.

2009; Forland et al., 2014). They are also consistent with the conceptual and theoretical models by Gorska et al. (2007) and Korneliussen (2010), wherein flesh and bone dominate scattering in different portions of our sampled band and the observed spectrum is a complicated superposition of the TS $(f)$ for these two kinds of fluid-like scattering structures. The consistency between mackerel and butterfish backscatter suggests common scattering mechanisms for fish without a gas-filled swimbladder, and provides confidence that these can be extended to other vertebrate (and possibly invertebrate) species with similar anatomical traits (sensu Gorska et al., 2005).

The KRM model predicts TS when the target conforms to the Kirchhoff approximations (i.e. $g$ and $h$ values not close to 1 , and broadside incidence), but prediction accuracy can deteriorate when those approximations are not met (Jech et al., 2016). We selected the KRM model because it can accommodate digital representations of the fish and anatomical features within the fish, rather than simplifying the overall morphology to a prolate spheroid or bent cylinder (e.g. Gorska et al., 2005), and without knowledge of the orientation distribution of in-situ butterfish, predictions were constrained to dorsal incidence. The KRM predictions of butterfish scattering were consistent with our mean empirical spectrum (after appropriate scaling), as well as the earlier models of backscatter by Atlantic mackerel (Gorska et al., 2007; Korneliussen, 2010). However, given the uncertainty in material properties of butterfish flesh and vertebrae and that butterfish can be considered weak scatterers (i.e. $g$ and $h$ values close to 1), more work is required to improve confidence in model predictions. For example, empirical studies of the material properties can be used in sensitivity analyses of model predictions by analytical models specifically developed for weakly scattering targets, such as the DWBA (Chu et al., 1993; Stanton et al., 1993) or its variants (phase-tracking DWBA, Jones et al., 2009; Stochastic DWBA, Demer and Conti, 2003), or numerical models such as the boundary element method (e.g. Francis and Foote, 2003) or finite element method (e.g. Macaulay et al., 2013). Selection of appropriate analytical or numerical models depends on a number of factors, such as computing power, availability of $3 \mathrm{D}$ digital representations of anatomical features, and material properties (Jech et al., 2016), but scattering models are necessary for understanding the empirical spectral patterns as well as improving predictive capability for a wide variety of environmental and biological conditions that may be encountered throughout resource surveys. With better characterization of the scattering properties of butterfish, algorithms (e.g. De Robertis et al., 2010; Trenkel and Berger, 2013) can be developed to classify butterfish in broadband and narrowband data.

Similar to Simrad's General Purpose Transceivers (GPTs), the WBTs can be transmitted simultaneously or sequentially. Multiple narrowband (i.e. multifrequency) systems are typically transmitted simultaneously to achieve consistent sampling volumes among systems where cross-talk is usually not an issue (i.e. frequencies are selected so that they are not within the bandwidth of each other and so they are also away from harmonics). Multiple broadband systems can have overlap among bandwidths, especially at the band edges, and can overlap harmonics, which may contribute to system noise. More studies are needed to ascertain the factors that affect bandwidth and whether the useful bandwidths are inherent to each specific transducer, WBT, our experiment, or a combination of acoustical and environmental conditions. During a pass over a euphausiid aggregation, we transmitted simultaneously for the first portion of that pass and sequentially for the remainder of that pass (Figure 5). The spectra from the different portions of the euphausiid aggregation did not show evidence of cross-talk among channels, suggesting configurations and processing methods are available to minimize interference among channels. Noise spikes were evident at consistent frequencies throughout the measurements. These spikes were not at the nominal centre frequencies of the bands, and highlight the need to be mindful of noise that may interfere across a wider band. The SNR for the features were marginally acceptable, especially for the butterfish aggregation. At $160 \mathrm{~m}$ range, the SNR at the higher frequencies (e.g. $>200 \mathrm{kHz}$ ) was less than $10 \mathrm{~dB}$. Our transmit source levels were set to avoid non-linear effects (Tichy et al., 2003), especially at the higher frequencies, primarily due to uncertainty in the response of each transducer to increased power levels. More study is needed to find optimal power levels for the transducers and applications. The measured spectra were 

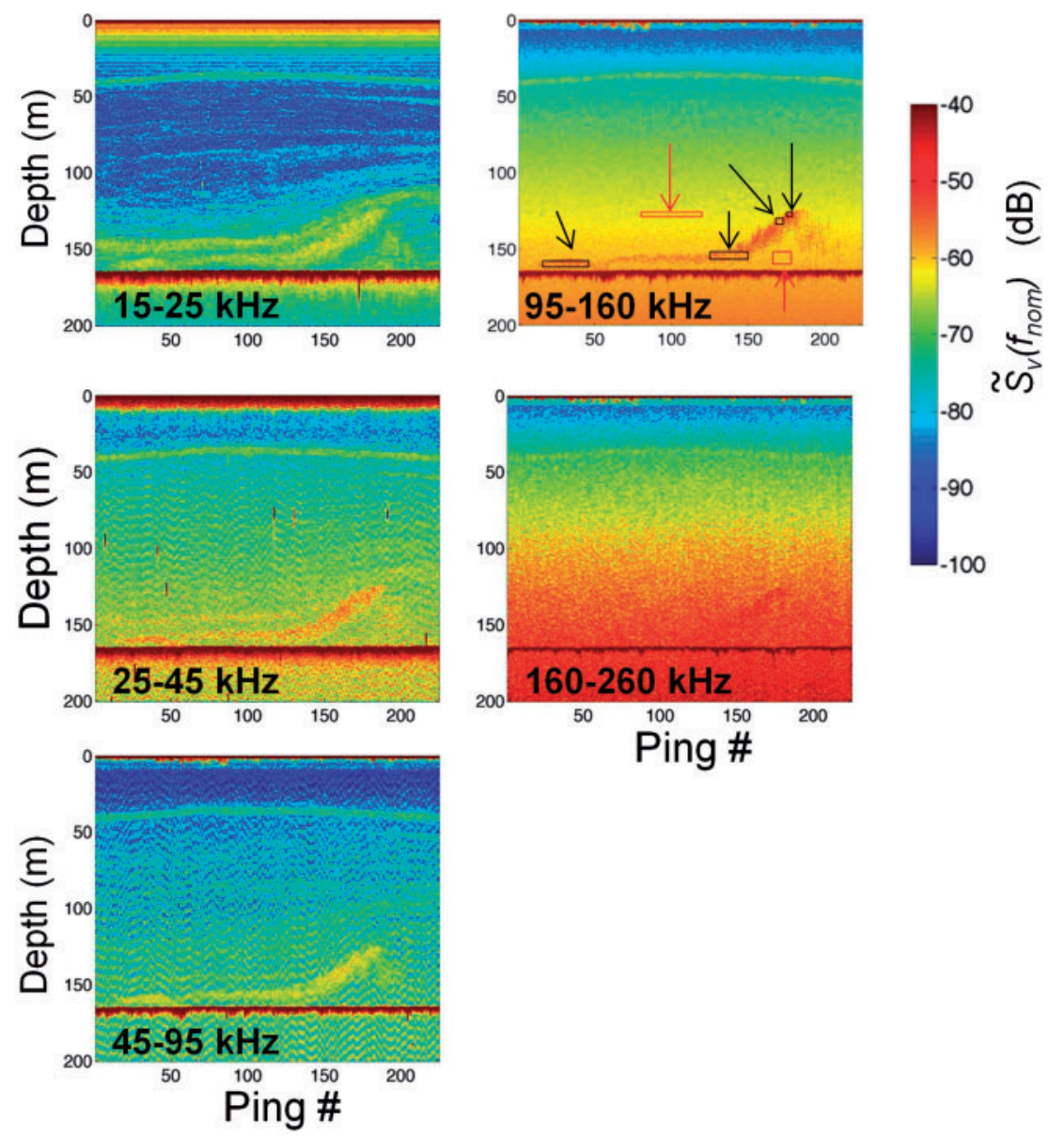

Figure 9. Scaled compressed-pulse output $\left[\tilde{S}_{\mathrm{v}}\left(f_{\text {nom }}\right)\right]$ echograms of broadband data collected from 1700 to 1714 (EST) on January 10 . All data were collected pinging sequentially. The scattering feature near the bottom (to the left) and rising to about $140 \mathrm{~m}$ depth (to the right) is butterfish. Black boxes represent regions where spectra were calculated within this butterfish layer and red boxes indicate regions at two different depths representing "open" water for which spectra were calculated and used as approximations of noise levels.

contiguous across the bands of the five separate channels, confirming the overall validity of their respective calibrations, although some of the variability within band may relate to calibration uncertainty (e.g. the $45-95 \mathrm{kHz}$ band for the euphausiid patch showed a consistent s-shape not expected from the theoretical scattering model).

We observed consistency in the euphausiid and butterfish spectral shapes at various locations within each aggregation, which suggests homogeneity of sizes, behaviour, and likely species within those patches/aggregations. An overarching paradigm of fish and zooplankton groups is that individuals tend to associate with others of the same species and similar sizes (Pitcher, 2001) and although heterospecific fish and zooplankton aggregations and layers are not uncommon (e.g. Lavery et al., 2007; Stanton et al., 2012), fine-scale segregation by species within those heterospecific aggregations has been observed (Parrish, 1989). Acoustic methods have been able to measure and characterize acoustic scattering patterns within aggregations (e.g. Stanton et al., 2010) at the sub-metre scale (e.g. Benoit-Bird, 2009a, b; Lavery et al., 2010). Now with widely available wideband technology, that resolution improves to centimetre scale which facilitates observations of the internal structure of fish and zooplankton aggregations at ever finer vertical resolution.
Although comparisons of the shapes of the scattering response curves based on acoustic scattering theory and organism anatomy to the corresponding backscattering spectra were reasonable, the magnitude of the $S_{\mathrm{v}}(f)$, when scaled by numeric density measures from net catches [i.e. conversion from $\operatorname{TS}(f)$ to $S_{\mathrm{v}}(f)$ ], did not match the mean spectra. There are numerous potential reasons for this mismatch, including within-aggregation patchiness, unknown and/or species-specific net catchability, and differences in sampling volumes (spatially and temporally) between nets and acoustics. In the present application, for instance, the magnitude of scattering spectra was observed to vary within the euphausiid aggregation, indicative of variations in animal packing density. Within one portion of the patch, from comparisons of theoretical to measured spectra, the average density of euphausiids can be estimated as $\sim 700$ ind $\mathrm{m}^{-3}$. These are relatively high densities and much higher than measured by net samples collected in the vicinity of the patch (likely due to a combination of the nets missing the main patch and avoidance), but previous density estimates for M. norvegica as well as the Antarctic krill (E. superba; another large species of euphausiid known to avoid small and slow-moving nets) made from visual, photograph, and acoustic observations are usually much higher than those made with nets (see review in Watkins, 2000; Wiebe et al., 2013). 


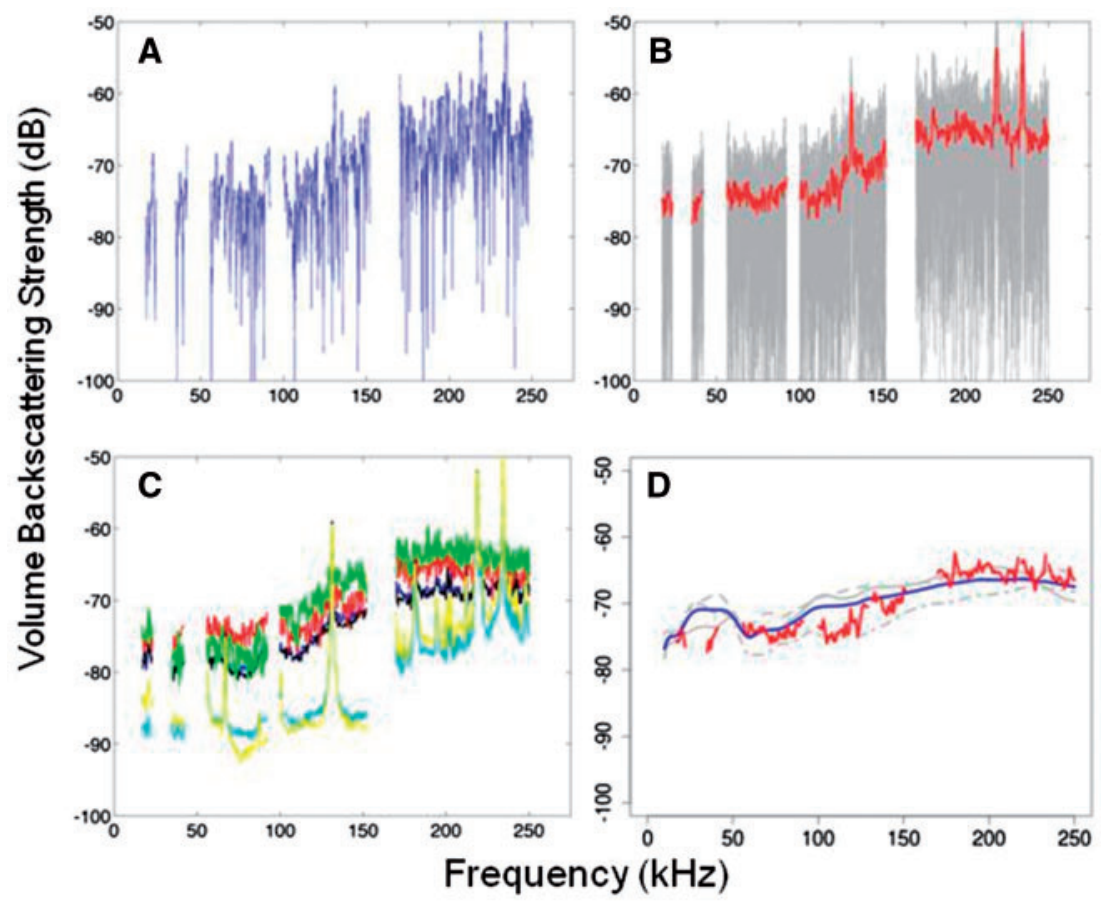

Figure 10. Volume backscattering spectra $\left[S_{v}(f)\right]$ from the highlighted regions in Figure 8 and KRM TS response curves. Panel (a) shows the spectrum from a single ping (ping number 168 in Figure 8) and averaged over a single 1-m depth bin within the butterfish layer. Panel (b) shows the spectra (grey lines) from all 1-m depth bins within a 6 ping $\times 4 \mathrm{~m}$ in depth region of the butterfish layer (pings 168-173 and 130-134 $\mathrm{m}$ in Figure 8) and the mean spectrum for this region (red line). Panel (c) shows spectra from different regions of varying sizes and depths within the butterfish layer (red line as in panel (b), blue, black, and green lines corresponding to pings 16-46 and depths 158-162 m, pings 125-150 and 152-157 m, and pings 175-179 and 126-129 m, respectively); and two spectra from outside the layer in "open" water but at similar depths to where butterfish spectra were calculated (cyan and yellow lines, pings 80-120 and 126-129 m in depth and pings $166-$ 178 and 152-160 m, respectively). These latter spectra were used to approximate noise levels. Panel (d) shows the mean butterfish spectrum with noise spikes removed for clarity of presentation and averaged into $1-\mathrm{kHz}$ frequency bins (red line, as in panel b), individual KRM TS response curves weighted by the butterfish length-frequency distribution for the three radiographed butterfish (live 142-mm denoted by the solid grey line, frozen $165-\mathrm{mm}$ denoted by the dashed grey line, and frozen 145 - $\mathrm{mm}$ denoted by the dash-dot grey line), and the mean lengthfrequency-weighted KRM TS response curve (blue line). The KRM TS response curves were scaled by $-8 \mathrm{~dB}$ (ca. 0.16 ind $\mathrm{m}^{-3}$ ) to match the magnitude of the mean $\operatorname{Sv}(f)$ spectra.

In the case of butterfish, the trawl catch suggested greater densities than that measured by the EK80. The length-weighted $\mathrm{TS}(f)$ needed to be scaled by $-8 \mathrm{~dB}\left(0.16\right.$ ind $\left.\mathrm{m}^{-3}\right)$ to match the measured backscatter amplitude. A bottom trawl was conducted in the same location as the observed butterfish scattering feature (Figure 9), but $5 \mathrm{~h}$ earlier during daylight hours. Using the swept volume (Jech and Sullivan, 2014) from that tow, a butterfish density of 1.9 ind $\mathrm{m}^{-3}$ was estimated, giving a scaling factor of $2.8 \mathrm{~dB}$. The order of magnitude difference between these two scaling factors is most likely due to the nocturnal vertical migration behaviour of butterfish, where butterfish are typically on the seabed during daylight hours and rise above the seabed (e.g. Figure 9) at dusk. Examination of the narrowband $200-\mathrm{kHz}$ volume backscatter data collected by Karen Elizabeth immediately prior to the trawl showed a $0.5-1 \mathrm{~m}$ thick layer of butterfish on the seabed with a maximum of $-36 \mathrm{~dB}$. During the ascent, the layer expanded vertically (Figure 9) and narrowband data immediately following wideband data collection on the scattering feature (Figure 9) showed multiple aggregations off the seabed with maximum values ranging from -41 to $-47 \mathrm{~dB}$. The $5-10 \mathrm{~dB}$ difference in volume backscatter between butterfish on vs. above the seabed is likely due to changes in packing density. Orientation of the butterfish is another factor, but the observed difference is commensurate with the difference in scaling factors needed to match model-based TS $(f)$ to the volume backscattering measurements, so a change in packing density is the more likely cause.

Over the decades since COTS multifrequency systems became available, multifrequency narrowband data have been collected during marine resource surveys and studies of marine ecology, and methods have been developed to classify these data to the lowest taxonomic level possible. In most cases, species identification is not possible, but classification to family or genus or scattering type (e.g. gas-bearing, fluid-like) has been useful for fisheries management, research, and addressing ecological questions (Trenkel et al., 2011 and references therein). Frequency dependent backscatter by fluid-like scatterers has been exploited to separate fluid-like scatterers from gas-bearing scatterers (e.g. Madureira et al., 1993), discriminate multiple scattering types (e.g. Korneliussen and Ona, 2003; De Robertis et al., 2010), or generate acoustic indicators (e.g. Trenkel and Berger, 2013). The progression from single to multiple narrowband to wideband data certainly provides more signal and data, but whether more 
data translates to more useful information and better classification remains an open question. For example, simply adding more narrowband frequency information does not necessarily improve length-based abundance estimates (Horne and Jech, 1999), and broadband data solely within the geometric scattering region of a fish does not necessarily improve species identification (e.g. Simmonds et al., 1996). This is because to maximize the information content, the ratio of organism size to acoustic frequency must span the transition region (where the acoustic wavelength is similar to the size of the object) from Rayleigh to geometric scattering (Holliday and Pieper, 1995), or at a minimum include scattering features such as resonance peaks (Stanton et al., 2010), that are useful for inversions (Horne and Jech, 1999).

Judicious choice of narrowband echosounders can lead to successful classification, so why make the switch to wideband? Wideband data can be used to fill in the gaps between multiple narrow bands, and conversely, volume backscattering levels at the bands that match historical narrowband data can be selected and used to estimate parameters for classification algorithms. For the euphausiids encountered during our measurements, selecting narrowband data at centre frequencies commonly used for fisheries surveys (e.g. 18, 38, 120, $200 \mathrm{kHz}$ ) map the Rayleigh to geometric scattering regions quite well, so one can contend that wideband data are not advantageous and are more costly in terms of data storage, electronic requirements, and processing than multiple narrowband systems. For example, when the species of interest is in monospecific aggregations, estimates of scatterer density and abundance are quite satisfactory and robust using narrowband data, whereas broadband information may be unnecessarily complex for these estimates and it actually may be more effective to reduce broadband to narrowband when estimating abundance for fisheries assessments or other needs. However, when species are mixed, broadband information may be useful for classification and selecting data to be used in abundance estimates (Stanton et al., 2012). For our data, by filling in the gaps between narrow bands, we know that the acoustic response is monotonically increasing from 18 to $38 \mathrm{kHz}$ (i.e. neither is a peak or valley in the spectrum which could indicate a resonance by small bubbles or gas-filled swimbladders) and the transition from Rayleigh to geometric scattering can be more accurately located, which provides a better estimate of euphausiid size than with multiple narrow bands. The wideband spectrum arguably contains more information for the butterfish than multiple narrow bands. The butterfish spectrum would be difficult to decipher and especially the inflection between 120 and $160 \mathrm{kHz}$ would be difficult to detect without the wideband data. The frequency of the transition may be dependent on the material properties and length of the fish (e.g. Gorska et al., 2007; Korneliussen, 2010) and may be useful for sizing the butterfish and discriminating butterfish from other fish without gas-filled swimbladders.

\section{Acknowledgements}

We thank Nicole Charriere for assistance at sea, Captain Chris Roebuck for sharing his fishing and acoustic expertise for finding and fishing butterfish, Jeff Condiotty and Lars N. Andersen of Kongsberg Underwater Technology Inc. (aka Simrad) for use of the EK80 WBTs, Doug Nowacek (Duke University) and Tom Weber (University of New Hampshire) for transducer loans (as well as advice concerning the use of the lower frequency channels in broadband mode from Weber), Shannon Crosby and
Nancy Copley for assistance with euphausiid length measurements, Kristy Owen for butterfish radiographs, and the ICES WG-FAST for enlightened discussion.

\section{Funding}

NOAA Advanced Sampling Technology Working Group (ASTWG) provided support for this project. GLL was partially supported by NOAA Cooperative Agreements NA09OAR4320129 and NA14OAR4320158 through the NOAA Fisheries Quantitative Ecology and Socioeconomics Training (QUEST) programme.

\section{References}

Benoit-Bird, K. J. 2009a. Dynamic 3-dimensional structure of thin zooplankton layers is impacted by foraging fish. Marine Ecology Progress Series, 396: 61-76.

Benoit-Bird, K. J. 2009b. The effects of scattering-layer composition, animal size, and numerical density on the frequency response of volume backscatter. ICES Journal of Marine Science, 66: 582-593.

Calise, L. 2009. Multifrequency acoustic target strength of northern krill. PhD thesis, University of Bergen, Norway. 338 pp.

Chu, D., Foote, K. G., and Stanton, T. K. 1993. Further analysis of target strength measurement of Antarctic krill at 38 and $120 \mathrm{kHz}$ : Comparison with deformed cylinder model and inference of orientation distribution. Journal of the Acoustical Society of America, 93: 2985-2988.

Chu, D., and Stanton, T. K. 1998. Application of pulse compression techniques to broadband acoustic scattering by live individual zooplankton. Journal of the Acoustical Society of America, 104: 39-55.

Clay, C. S., and Horne, J. K. 1994. Acoustic models of fish: the Atlantic cod (Gadus morhua). Journal of the Acoustical Society of America, 96: 1661-1668.

Clay, C. S., and Medwin, H. 1977. Acoustical Oceanography: Principles and Applications. John Wiley and Sons, Inc., New York, USA. 544 pp.

Conti, S. G., and Demer, D. A. 2003. Wide-bandwidth acoustical characterization of anchovy and sardine from reverberation measurements in an echoic tank. ICES Journal of Marine Science, 60: 617-624.

Conti, S. G., Demer, D. A., and Brierley, A. S. 2005. Broad bandwidth sound scattering and absorption from krill (Meganyctiphanes norvegica), Mysids (Praunus flexuousus and Neomysis integer) and shrimp (Crangon crangon). ICES Journal of Marine Science, 62: 956-965.

Cushing, D. H. 1973. The Detection of Fish. Pergamon Press, Ltd., Oxford, UK. 200 p.

Demer, D. A., and Conti, S. 2003. Reconciling theoretical versus empirical target strength of krill: effects of phase variability on the distorted wave Born approximation. ICES Journal of Marine Science, 61: 157-158.

Demer, D. A., et al. 2015. Calibration of acoustic instruments. ICES Cooperative Research Report No. 326. 133 pp.

De Robertis, A., McKelvey, D. R., and Ressler, P. H. 2010. Development and application of an empirical multifrequency method for backscatter classification. Canadian Journal of Fisheries and Aquatic Sciences, 67: 1459-1474.

Ehrenberg, J. E., and Torkelson, T. C. 2000. FM slide (chirp) signals: a technique for significantly improving the signal-to-noise performance in hydroacoustic assessment systems. Fisheries Research, 47: 193-199.

Foote, K. G., Knudsen, H. P., Vestnes, G., MacLennan, D. N., and Simmonds, E. J. 1987. Calibration of acoustic instruments for fish density estimation: a practical guide. ICES Cooperative Research Report, 144: 69. 
Forland, T. N., Hobæk, H., and Korneliussen, R. J. 2014. Scattering properties of Atlantic mackerel over a wide frequency range. ICES Journal of Marine Science, 71: 1904-1912.

Francis, D. T. I., and Foote, K. G. 2003. Depth-dependent target strengths of gadoids by the boundary-element method. Journal of the Acoustical Society of America, 114: 3136-3146.

Francois, R. E., and Garrison, G. R. 1982a. Sound absorption based on ocean measurements: Part I: pure water and magnesium sulfate contributions. Journal of the Acoustical Society of America, 72: 896-907.

Francois, R. E., and Garrison, G. R. 1982b. Sound absorption based on ocean measurements: Part II: Boric acid contribution and equation for total absorption. Journal of the Acoustical Society of America, 72: 1879-1890.

Gorska, N., Ona, E., and Korneliussen, R. 2005. Acoustic backscattering by Atlantic mackerel as being representative of fish that lack a swimbladder. Backscattering by individual fish. ICES Journal of Marine Science, 62: 984-995.

Gorska, N., Korneliussen, R. J., and Ona, E. 2007. Acoustic backscatter by schools of adult Atlantic mackerel. ICES Journal of Marine Science, 64: 1145-1151.

Holliday, D. V., Pieper, R. E., and Kleppel, G. S. 1989. Determination of zooplankton size and distribution with multifrequency acoustic technology. Journal du Conseil pour l'international Exploration de la Mer, 46: 52-61.

Holliday, D. V., and Pieper, R. E. 1995. Bioacoustical oceanography at high frequencies. ICES Journal of Marine Science, 52: 279-296.

Horne, J. K., and Jech, J. M. 1999. Multi-frequency estimates of fish abundance: constraints for rather high frequencies. ICES Journal of Marine Science, 56: 184-199.

Jech, J. M., and Horne J. K., 1998. Sensitivity of Acoustic Scattering Models to Fish Morphometry. in Proceedings 16th International Congress on Acoustics and 135th Meeting Acoustical Society of America, 20-26 June 1998, Seattle, WA, USA. Vol 3, pp. 18191820.

Jech, J. M., Horne, J. K., Chu, D., Demer, D. A., Francis, D. T. I., Gorska, N., Jones, B., Lavery, A. C., Stanton, T. K., Macaulay, G. J., Reeder, D. B., and Sawada, K. 2016. Comparisons among ten models of acoustic backscattering used in aquatic ecosystem research. Journal of the Acoustical Society of America, 138: 3742-3764.

Jech, J. M., and Sullivan, P. J. 2014. Distribution of Atlantic herring (Clupea harengus) in the Gulf of Maine from 1998-2012. Fisheries Research, 156: 26-33.

Jones, B. A., Lavery, A. C., and Stanton, T. K. 2009. Use of the distorted wave Born approximation to predict scattering by inhomogeneous objects: Application to squid. Journal of the Acoustical Society of America, 125: 73-88.

Kjærgaard, N., Bjrn, L., Kirkegaard, E., and Lassen, H. 1990. Broadband analysis of acoustical scattering by individual fish. Rapport P.-v. Reunion Conseil de l'international Explore de la Mer, 189: 370-380.

Korneliussen, R. J. 2010. The acoustic identification of Atlantic mackerel. ICES Journal of Marine Science, 67: 1749-1758.

Korneliussen, R. J., and Ona, E. 2003. Synthetic echograms generated from the relative frequency response. ICES Journal of Marine Research, 60: 636-640.

Lawson, G. L., Wiebe, P. H., Ashjian, C. J., Chu, D., and Stanton, T. K. 2006. Improved parameterization of Antarctic krill target strength models. Journal of the Acoustical Society of America, 119: 232-242.

Lawson, G. L., Wiebe, P. H., Stanton, T. K., and Ashiian, C. J. 2008. Euphausiid distribution along the Western Antarctic PeninsulaPart A: development of robust multi-frequency acoustic techniques to identify euphausiid aggregations and quantify euphausiid size, abundance, and biomass. Deep-Sea Research II, 55: 412-431.
Lavery, A. C., Wiebe, P. H., Stanton, T. K., Lawson, G. L., Benfield, M. C., and Copley, N. 2007. Determining dominant scatterers of sound in mixed zooplankton populations. Journal of the Acoustical Society of America, 122: 3304-3326.

Lavery, A. C., Chu, D., and Moum, J. N. 2010. Measurements of acoustic scattering from zooplankton and oceanic microstructure using a broadband echosounder. ICES Journal of Marine Science, 67: 379-394.

Lavery, A. C., Bassett, C., Lawson, G. L., and Jech J. M., 2017. Exploiting signal processing approaches for broadband echosounders, ICES Journal of Marine Science, 74: 2262-2275.

Love, R. H. 1975. Predictions of volume scattering strengths from biological trawl data. Journal of the Acoustical Society of America, 57: 300-306.

Lunde, P., Pedersen, A. O., Korneliussen, R. J., Tichy, F. E., and Nes H., 2013. Power-budget and echo-integrator equations for fish abundance estimation. Fisken og Havet no. 10/2013, Institute of Marine Research, Bergen, Norway, 39 p.

Lundgren, B., and Nielsen, J. R. 2008. A method for the possible species discrimination of juvenile gadoids by broad-bandwidth backscattering spectra vs. angle of incidence. ICES Journal of Marine Science, 65: 581-593.

Macaulay, G. J., Peña, H., Fässler, S. M. M., Pedersen, G., and Ona, E. 2013. Accuracy of the Kirchhoff-approximation and Kirchhoffray-mode swimbladder scattering models. PLoS One, 8: e64055. doi:10.1371/journal.pone.0064055.

Madureira, L. S. P., Everson, I., and Murphy, E. J. 1993. Interpretation of acoustic data at two frequencies to discriminate between Antarctic krill (Euphausia superba Dana) and other scatterers. Journal of Plankton Research, 15: 787-802.

Mauchline, J. 1980. Measurement of body length of Euphausia superba Dana, BIOMASS Handbook, 4: 4-9.

Nero, R. W., Thompson, C. H., and Jech, J. M. 2004. In situ estimates of the swimbladder volume of Atlantic herring (Clupea harengus). ICES Journal of Marine Science, 62: 323-337.

Nesse, T. L., Hobæk, H., and Korneliussen, R. J. 2009. Measurements of acoustic-scattering spectra from the whole and parts of Atlantic mackerel. ICES Journal of Marine Science, 66: 1169-1175.

Parrish, J. K. 1989. Layering with depth in a heterospecific fish aggregation. Environmental Biology of Fishes, 26: 79-85.

Pitcher, T. J. 2001. Fish Schooling, in Encyclopedia of Ocean Sciences, Ed. by J. H. Steele, K. K. Turekian, and S. A. Thorpe. Academic Press, UK, pp. 975-987.

Politis, P. J., Galbraith, J. K., Kostovick, P., and Brown R. W., 2014. Northeast Fisheries Science Center bottom trawl survey protocols for the NOAA Ship Henry B Bigelow. US Dept. Commer, Northeast Fisheries Science Center Reference Document. 14-06: $138 \mathrm{pp}$.

Posgay, J. A., and Marak, R. R. 1980. The MARMAP bongo zooplankton samplers. Journal of Northwest Atlantic Fisheries Science, 1: 91-99.

Reeder, D. B., Jech, J. M., and Stanton, T. K. 2004. Broadband acoustic backscatter and high-resolution morphology of fish: measurement and modeling. Journal of the Acoustical Society of America, 116: 747-761.

Simmonds, E. J., and Armstrong, F. 1990. A wideband echo sounder: measurements on cod, saithe, herring, and mackerel from 27 to $54 \mathrm{kHz}$. Rapport P.-v. Reunion Conseil de l'international Explore de la Mer, 189: 381-387.

Simmonds, E. J., Armstrong, F., and Copland, P. J. 1996. Species identification using wideband backscatter with neural network and discriminant analysis. ICES Journal of Marine Science, 53: 189-195.

Stanton, T. K. 2009. Broadband acoustic sensing of the ocean. Journal of the Marine Acoustical Society of Japan, 36: 95-107. 
Stanton, T. K., and Chu, D. 2008. Calibration of broadband active acoustic systems using a single standard spherical target. Journal of the Acoustical Society of America, 124: 128-136.

Stanton, T. K., Chu, D., Wiebe, P. H., and Clay, C. S. 1993. Average echoes from randomly oriented random-length finite cylinders: Zooplankton models. Journal of the Acoustical Society of America, 94: 3463-3472.

Stanton, T. K., Chu, D., Jech, J. M., and Irish, J. D. 2010. New broadband methods for resonance classification and high-resolution imagery of fish with swimbladders using a modified commercial broadband echosounder. ICES Journal of Marine Science, 67: 365-378.

Stanton, T. K., Reeder, D. B., and Jech, J. M. 2003. Inferring fish orientation from broadband-acoustic echoes. ICES Journal of Marine Science, 60: 524-531.

Stanton, T., K., Sellers, C. J., and Jech J. M., 2012. Resonance classification of mixed assemblages of fish with swimbladders using a modified commercial broadband acoustic echosounder at 1$6 \mathrm{kHz}$. Canadian Journal of Fisheries and Aquatic Sciences, 69: $854-868$.

Stanton, T. K., Wiebe, P. H., Chu, D., Benfield, M. C., Scanlon, L., Martin, L., and Eastwood, R. L. 1994. On acoustic estimates of zooplankton biomass. ICES Journal of Marine Science, 51: 505-512.

Tichy, F. E., Solli, H., and Klaveness, H. 2003. Non-linear effects in a $200-\mathrm{kHz}$ sound beam and the consequences for target-strength measurements. ICES Journal of Marine Science, 60: 571-574.

Trenkel, V. M., Ressler, P. H., Jech, M., Giannoulaki, M., and Taylor, C. 2011. Underwater acoustics for ecosystem-based management: state of the science and proposals for ecosystem indicators. Marine Ecology Progress Series, 442: 285-301.

Trenkel, V. M., and Berger, L. 2013. A fisheries acoustic multifrequency indicator to inform on large scale spatial patterns of aquatic pelagic ecosystems. Ecological Indicators, 30: 72-79.

Turin, G. L. 1960. An introduction to matched filters. IRE Transactions on Information Theory, 6: 311-329.

Urick, R. J. 1983. Principles of Underwater Sound. Peninsula Publishing, Los Altos, California, USA. 423 pp.

Watkins, J. L. 2000. Aggregation and vertical migration. In Krill: Biology, Ecology and Fisheries. Ed. by I. Everson. Blackwell Science, Oxford, pp. 80-102.

Wiebe, P. H., Lawson, G. L., Lavery, A. C., Copley, N. J., Horgan, E., and Bradley, A. 2013. Improved agreement of net and acoustical methods for surveying euphausiids by mitigating avoidance using a net based LED strobe light system. ICES Journal of Marine Science, 70: 650-664.

Wigley, S. A., McBride, H. M., and McHugh, N. J., 2003. Lengthweight relationships for 74 fish species collected during NEFSC research vessel bottom trawl surveys, 1992-99. NOAA Technical Memorandum NMFS-NE-171. 36 pp.

Wright, J., and Colling A., 1995. Seawater: Its Composition, Properties and Behaviour. The Open University, Pergamon Press, Ltd., Oxford, UK. 167 pp.

Zakharia, M. E., Magand, F., Hetroit, F., and Diner, N. 1996. Wideband sounder for fish species identification at sea. ICES Journal of Marine Science, 53: 203-208. 